\title{
Ações para mitigar resíduos sólidos em terrenos baldios de Campina Grande/PB
}

A deposição dos resíduos em áreas impróprias, a exemplo de terrenos baldios, é um problema cada vez mais evidente. Acredita-se que esta prática pode ser reflexo de falhas na educação ambiental. Amparado nesta problemática, o objetivo deste estudo foi verificar ações para mitigar a deposição de resíduos sólidos em terrenos baldios de Campina Grande (PB). Para tanto, o estudo foi desenhado por meio do método indutivo, com apoio da pesquisa exploratória e descritiva, de abordagem qualitativa. Os dados foram colhidos entre julho e novembro de 2019, por meio de entrevistas gravadas e com preenchimento de formulários junto à coordenação da Vigilância Ambiental, Vigilância Epidemiológica e Secretaria de Serviços Urbanos e Meio Ambiente (SESUMA) de Campina Grande (PB). A partir dessas informações, foi realizado um reconhecimento espacial da cidade, através do programa Google Earth ${ }^{\oplus}$, por meio do qual a localidade dos bairros e terrenos baldios foi delimitada, previamente observada, e, posteriormente, visitada e fotografada. Os resultados da pesquisa foram descritos e discutidos à luz da literatura e, posteriormente, interpretados de acordo com a análise de conteúdo proposta por Bardin. O presente estudo foi cadastrado na Plataforma Brasil, submetido ao Comitê de Ética em Pesquisa e aprovado. A vigilância Ambiental forneceu todo o mapeamento de Campina Grande com a localização de 2.453 terrenos baldios dispersos no município e apresentou suas principais ações de combate a esta problemática. A Vigilância Epidemiológica informou que o registro de notificação compulsória de doenças correlacionadas ao acúmulo de resíduos sólidos tem aumentado entre os anos 2014 e 2018 . A dengue, por exemplo, cresceu $456,9 \%$ em 2018 comparada a 2017. Os dados colhidos na SESUMA geraram três categorias: resíduos sólidos em terrenos baldios; educação ambiental e penalidades e, indicadores de sustentabilidade ambiental. A fim de mitigar a deposição inadequada de resíduos sólidos em terrenos baldios, a Vigilância Ambiental sugere notificações e multas, bem como fazer valer o Código de Postura do município. A Vigilância Epidemiológica recomenda fazer campanhas mais impetuosas que estimulem práticas de educação ambiental. A SESUMA propõe-se a execução de ações mais próximas e efetivas nas áreas de educação, saúde e meio ambiente.

Palavras-chave: Meio ambiente; Espaços urbanos; Resíduos sólidos; Educação ambiental.

\section{Actions to mitigate solid waste on empty land of Campina Grande/PB}

\begin{abstract}
The deposition of waste in inappropriate areas, such as vacant lots, is an increasingly evident problem. It is believed that this practice may reflect flaws in environmental education. Supported by this problem, the objective of this study was to verify the actions to mitigate the deposition of solid waste in vacant lots in Campina Grande (PB). To this end, the study was designed using the inductive method, with support from exploratory and descriptive research, with a qualitative approach. Data were collected between July and November 2019, through recorded interviews and filling out forms with the coordination of Environmental Surveillance, Epidemiological Surveillance and the secretary of urban services and environment of Campina Grande (PB). From this information, a spatial recognition of the city was carried out, through the Google Earth ${ }^{\circledR}$ program, where the locality of the neighborhoods and vacant lots was defined, previously observed, and subsequently visited and photographed. The data were described and discussed in the light of the literature and, subsequently, interpreted according to the content analysis proposed by Bardin. This study was registered at Platform Brazil, submitted to the Research Ethics Committee and approved. Environmental surveillance provided the entire mapping of Campina Grande with the location of 2,453 wasteland scattered in the municipality and presented its main actions to combat this problem. The Epidemiological Surveillance reported that the record of compulsory notification of diseases related to the accumulation of solid waste has increased between the years 2014 and 2018. Dengue, for example, grew 456.9\% in 2018 compared to 2017. The data collected at Secretary of Urban Services and Environment generated three categories: solid waste in vacant lots; environmental education and penalties and environmental sustainability indicators. In order to mitigate the inadequate deposition of solid waste in vacant lots, the Environmental Surveillance suggests notifications and fines, as well as enforcing the municipality's Posture Code. Epidemiological Surveillance recommends to do more impetuous campaigns that encourage environmental education practices. The Secretary of Urban Services and Environment proposes to carry out closer and more effective actions in the areas of education, health and the environment.
\end{abstract}

Keywords: Environment; Urban spaces; Solid waste; Environmental education.

Topic: Educação Ambiental

Reviewed anonymously in the process of blind peer.
Received: 06/10/2020

Approved: $\mathbf{2 8 / 1 1 / 2 0 2 0}$

Flávia Nunes Ferreira de Araújo (iD)

Universidade Federal de Campina Grande, Brasil

http://lattes.cnpq.br/7664987364699358

http://orcid.org/0000-0002-5076-133X

flaviapsfcg@hotmail.com

Maria de Fátima Nóbrega Barbosa (iD

Universidade Federal de Campina Grande, Brasil

http://lattes.cnpq.br/8262057016878547

http://orcid.org/0000-0003-3415-8829

mfnbarbosa@hotmail.com

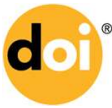

Referencing this:

ARAÚJO, F. N. F.; BARBOSA, M. F. N.. Ações para mitigar resíduos sólidos em terrenos baldios de Campina Grande/PB. Revista Ibero

DOI: 10.6008/CBPC2179-6858.2020.006.0056 Americana de Ciências Ambientais, v.11, n.6, p.700-715, 2020. DOI: http://doi.org/10.6008/CBPC2179-6858.2020.006.0056 


\section{INTRODUÇÃO}

A produção de resíduos sólidos faz parte do cotidiano do ser humano. No entanto, a geração de resíduos vem sendo cada vez mais acrescida devido ao aumento da população humana, à concentração das pessoas em centros urbanos, à forma e ao ritmo da ocupação desses espaços, assim como ao modo de vida com base na produção e consumo de bens de maneira desenfreada que tem se tornado uma adversidade para o meio ambiente (PHILIPPI JÚNIOR et al., 2005).

A deposição dos resíduos em áreas impróprias, a exemplo de terrenos baldios, é um problema cada vez mais evidente e o gerenciamento por parte dos órgãos públicos nem sempre é uma tarefa fácil (SILVA et al., 2010). Além da contaminação, o problema maior é o longo tempo de permanência do resíduo no ambiente, pois o processo de degradação desse material produz gases que têm fortes odores e atraem baratas, moscas, ratos e escorpiões, que segundo Souza et al. (2013) podem ser vetores mecânicos e biológicos de agentes etiológicos causadores de doenças, tais como: diarreias infecciosas, amebíase, giardíase, salmonelose, helmintoses, leptospirose, peste bubônica, além da dengue, zika e chikungunya. Estes vetores não ficam somente no acúmulo do resíduo, vão até as habitações mais próximas levando consigo uma série de consequências à saúde da população.

Para Souza et al. (2013), considera-se terrenos baldios áreas não cercadas, abandonadas com a presença ou não de vegetação. A ausência dos devidos cuidados de limpeza nesses terrenos torna-se um transtorno ambiental por atrair animais peçonhentos, insetos e roedores, resultando em um problema de saúde pública e ambiental. Essas áreas constituem também um ambiente potencialmente receptor de resíduos domésticos, uma vez que jogar esses materiais em terrenos baldios é um mau hábito comum na zona urbana. Esta atitude está inserida no contexto de falhas na educação ambiental, constituída como o ramo da educação focado em disseminar o conhecimento sobre o meio ambiente, na busca da preservação e utilização sustentável dos recursos naturais (RODRIGUES et al., 2004).

Philippi Júnior et al. (2002) dizem que a educação ambiental é um processo de ensino-aprendizagem para o exercício da cidadania. A ela cabe construir novos valores e novas relações sociais dos seres humanos com a natureza, formando atitudes dentro de uma nova ótica, a da melhoria da qualidade de vida para todos. Deve-se destacar a importância da educação ambiental nos programas de saneamento, uma vez que sem a participação popular dificilmente os mesmos obterão o êxito desejado.

Baseado nessa premissa, a interlocução entre a Vigilância Ambiental (VA), a Vigilância Epidemiológica (VE) e a Secretaria Municipal de Serviços Urbano e Meio Ambiente (SESUMA) é fundamental. A VA por permitir uma abordagem centrada na promoção e na proteção à saúde dos cidadãos, contribuindo para o pressuposto de saúde como direito universal, no qual está incluído o direito ao ambiente ecologicamente equilibrado (BRASIL, 2007). A VE objetiva principalmente o combate e controle das doenças, incluindo aquelas de ordem ambiental e fornecendo orientação técnica permanente para os profissionais de saúde (BRASIL, 2009). A, SESUMA, que tem como essência da sua função fiscalizar, executar políticas públicas infraestruturais e de urbanização, além de efetivar atividades relativas à orientação, controle e execução de 
obras públicas municipais realizadas por administração direta e aplicação dos códigos e normas referentes às edificações particulares, a estética urbana, segundo as diretrizes do Plano Diretor de Desenvolvimento Urbano Ambiental (PARAÍBA, 2006).

O diálogo entre a VA, VE e a SESUMA é importante porque cada entidade tem sua função e objetivos específicos, e juntas, podem unir forças e somar atribuições efetivas ao combate dessa problemática. Assim, este estudo se propôs a verificar as ações da VA, VE e SESUMA para mitigar a deposição de resíduos sólidos em terrenos baldios de Campina Grande-PB.

\section{METODOLOGIA}

\section{Método e classificação da pesquisa}

Quanto aos aspectos metodológicos, esta pesquisa foi organizada utilizando-se do método de abordagem indutiva e o estudo de caso como método de procedimento. A pesquisa iniciou-se por um levantamento bibliográfico no Google Scholar, em bancos de dados como SciELO - Scientific Electronic Library Online e repositórios de universidades. Também foi realizada uma seleção documental em Leis, Políticas Públicas, Relatórios de eventos científicos nacionais e internacionais, Resoluções, Diretrizes, Fotografias in loco, conforme exemplifica Gil (2008), que perpassou toda a elaboração deste trabalho, com o propósito de compreender para explicar a realidade estudada. Seguiu pela fase exploratória, descritiva e pesquisa de campo.

\section{Cenário do estudo e coleta de dados}

O ambiente da pesquisa foi a cidade de Campina Grande situada no agreste do Estado da Paraíba, estando a aproximadamente $120 \mathrm{~km}$ da capital, João Pessoa. De acordo com o Instituto Brasileiro de Geografia e Estatística (IBGE, 2019) o município conta com uma população estimada de 409.731 habitantes distribuídos em 51 bairros. O Índice de Desenvolvimento Humano (IDH) chegou a 0,720 no ano de 2010 e com o Produto Interno Bruto (PIB) de 21.077,30 reais (IBGE, 2019). As principais atividades econômicas estão distribuídas entre extração mineral, comércio varejista, culturas agrícolas, pecuária, indústrias de transformação, atacadista e serviços. Sua posição geográfica privilegiada contribui para ser um centro distribuidor e receptor de matéria-prima e mão-de-obra na região.

No aspecto da saúde, de acordo com o Cadastro Nacional de Estabelecimentos de Saúde (BRASIL, 2020), o município de Campina Grande conta com 735 estabelecimentos de saúde, sendo 22 hospitais entre públicos e privados, 109 Equipes de Saúde da Família, duas Unidades de Pronto Atendimento (UPAs), entre outros. O sistema de saúde de Campina Grande é subdividido geograficamente em oito Distritos Sanitários (DS) a partir de características epidemiológicas, sociais e suas necessidades, e dos recursos de saúde para atendê-la (Quadro1). 


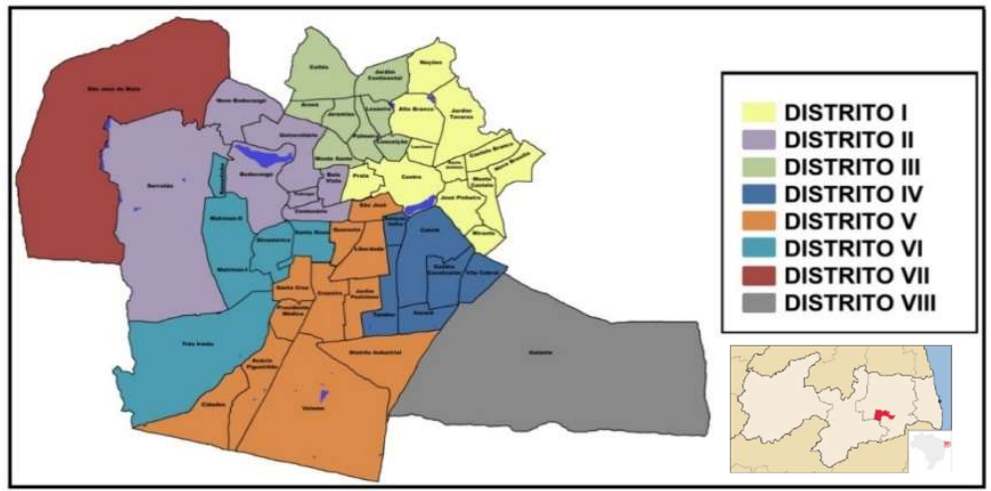

Quadro 1: Distribuição geográfica dos Distritos Sanitários em Campina Grande/PB, 2020.

A coleta de dados foi realizada por meio de entrevistas semiestruturadas aplicadas na VA, VE e SESUMA com o objetivo de conseguir informações que não seriam possíveis somente através da pesquisa bibliográfica e documental. Também foram realizados registros fotográficos em terrenos baldios que apresentavam resíduos sólidos no momento da pesquisa de campo.

A abordagem qualitativa se apresentou pertinente para se buscar respostas às questões colocadas para discussão. Para Malhotra (2006), a pesquisa qualitativa compreende a descrição da complexidade de determinado problema e a interação de certas variáveis, como também, busca entender e classificar a dinâmica vivida por grupos sociais, contribuindo no processo de mudança de uma determinada comunidade e possibilitar, em maior nível de profundidade, a compreensão das particularidades do comportamento dos indivíduos. A compreensão do sentido da entrevista qualitativa, de seus limites e potenciais, bem como a preparação para a sua execução, fora ancorada nas recomendações de Gaskell (2013).

O percurso da coleta de dados foi cumprido em quatro etapas: a primeira foi a visita junto à VA em busca de mapas geográficos de terrenos baldios com o objetivo de detectar áreas mais críticas em cada DS distribuído na zona urbana do município em estudo, além da realização da entrevista com a coordenação. A segunda etapa foi na VE a fim de captar dados secundários oriundos de registros no Sistema de Informação em Saúde com casos de notificação de doenças relacionadas à exposição de resíduos sólidos, transmitidas por insetos e roedores como moscas, mosquitos, ratos e baratas. Oportunamente, também foi realizada a entrevista com a coordenação. A terceira etapa foi a realização de visitas em terrenos baldios nos oito DS, onde pôde-se detectar e registrar fotograficamente a evidência de resíduos sólidos depositados em espaços urbanos 'vazios'. A quarta etapa da pesquisa contou com a participação da Coordenação da SESUMA no intuito de averiguar a efetividade das ações e estratégias para mitigar a situação de terrenos baldios com deposição de resíduos.

As Vigilâncias Ambiental e Epidemiológica localizam-se em prédios diferentes e em bairros distanciados. Para a realização da pesquisa foi necessário mais de uma visita em ambas as Vigilâncias. A primeira para apresentar o projeto, explanar o objetivo do estudo e escolher a melhor forma de registrar a coleta de dados, além de solicitar a autorização por escrito para a realização da pesquisa (carta de anuência), as demais visitas foram para agendamento da entrevista, assinatura do Termo de Consentimento Livre e Esclarecido (TCLE), realização da entrevista e coleta de dados no sistema de informação. 
A etapa dos registros fotográficos foi realizada após a coleta de informações na VA e VE, em que foi possível verificar a distribuição de terrenos baldios, seus respectivos endereços e a notificação de doenças correlacionadas ao contato direto ou indireto com resíduos sólidos em pessoas residentes em lugares próximos a esses terrenos. Foi realizado um reconhecimento espacial da cidade, através do programa Google Earth $^{\circledR}$, onde a localidade dos bairros e terrenos baldios foram delimitados e previamente observados. A partir disto, os terrenos foram visitados, para fins de registros fotográficos. Seguida a etapa de diagnóstico, foi feita a identificação de maneira simples dos principais tipos de resíduos gerados, assim como os pontos críticos onde mais se encontravam os resíduos (georreferenciados no Google Earth ${ }^{\circledR}$ ). Assim, utilizando o Sistema de Posicionamento Global (GPS), o georreferenciamento desses pontos serviu como instrumento para agilizar as visitas in loco que são ocupadas irregularmente pelos resíduos sólidos na área urbana de Campina Grande-PB. Como instrumento para coleta de dados dos registros fotográficos foi utilizado uma câmara de Smartphone.

Com base no princípio de saturação empírica (MINAYO, 2017), quando se percebeu a consistência das informações centrais e a relativa redundância das fotografias com características semelhantes, atingiu-se um número de registros fotográficos. Saturação é um termo criado por Glaser e Strauss (1967) para se referir a um momento no trabalho de campo em que a coleta de novos dados não traz mais esclarecimentos para o objeto estudado. Assim, foi registrado um total de 156 imagens, das quais, oito foram selecionadas para este estudo, utilizando-se como critério de inclusão, bairros com maiores casos notificados, terrenos baldios vizinhos a residências e a associação de doenças notificadas na VE relacionadas aos moradores do entorno. Os trabalhos de campo foram também oportunidade para diferentes observações e registro de notas, conjunto que inevitavelmente auxiliou na abordagem ora apresentada.

Por fim, a quarta etapa da pesquisa deu-se por meio de uma entrevista concedida pela Coordenação da SESUMA. Inicialmente, foi feito um ofício solicitando a disponibilidade do Secretário em participar da pesquisa e também explanando os objetivos do estudo. Após o deferimento do oficio, fez-se o agendamento da entrevista a qual foi gravada, com a devida permissão do entrevistado por meio da assinatura de Termo de Autorização para Gravação de Voz, assim como também foi firmado o Termo de Consentimento Livre e Esclarecido (TCLE).

As entrevistas e registros fotográficos foram realizados entre julho e novembro de 2019. Um dos obstáculos enfrentados na celeridade da pesquisa, os quais são comuns em pesquisas de campo, foram as questões burocráticas, elaboração de ofícios, aguardar retorno dos solicitados à pesquisa e, ainda, respeitando-se a data e horário de disponibilidade dos entrevistados. Todas as visitas na VA, VE e SESUMA foram realizadas com agendamentos prévios.

\section{Tratamento dos dados e aspectos éticos}

Foi realizado um criterioso exame durante a análise dos dados, respeitando-se eticamente todas as respostas. Na análise de conteúdo (BARDIN, 2015) se enfatizou a visão do colaborador acerca dos problemas ambientais e de saúde, provocados pelo acúmulo de resíduos em terrenos baldios e suas respectivas ações 
para mitigar está problemática.

Precedente à coleta de dados, o projeto de pesquisa foi cadastrado à Plataforma Brasil e submetido para apreciação do Conselho Nacional de Ética em Pesquisa - CONEP. O Comitê de Ética em Pesquisa do Centro de Ensino Superior e Desenvolvimento (CEP - CESED) aprovou o estudo e emitiu Parecer Consubstanciado. A pesquisa buscou garantir todas as Normas da Resolução 466/12 (BRASIL, 2012), no que diz respeito aos fundamentos éticos e científicos pertinentes, preservando o respeito e o sigilo do participante em todas as etapas da coleta de dados.

\section{Apresentação e discussão dos resultados}

\section{Vigilâncias ambiental e epidemiológica}

A coleta de dados junto à VA foi indispensável, pois está forneceu todo o mapeamento de Campina Grande com a localização de terrenos baldios dispersos no município. Esses números foram fornecidos em sua totalidade por DS, por bairro e, ainda por nome da rua, o que pôde facilitar a mediação entre pesquisador e visitação in loco para comprovação de acúmulo de resíduos em alguns destes locais. Na ocasião da coleta de dados, Campina Grande contava com 2.453 terrenos baldios.

A coordenação da VA de Campina Grande acredita que as pessoas depositam os resíduos sólidos em terrenos baldios porque não sabem o perigo à saúde e, também por inexistência de responsabilidade com o outro. Dessa forma, crescem os principais desafios da VA como expansão de criadouro de mosquitos, ratos, baratas, entre outros.

Para mitigar o depósito de resíduos sólidos em locais impróprios, a VA tem promovido ações educativas específicas a esta problemática, capacitações para agentes de combate das endemias, além de campanhas educativas em diversos meios de comunicação, com o intuito de atingir a população em massa. No entanto, a coordenação da VA especifica alguns indicadores ambientais que dificultam a efetividade de ações como domicílios improvisados, precário saneamento básico, animais domésticos sem os cuidados adequados e educação ambiental inconsistente. Além disso, as pessoas parecem não dar a devida atenção às advertências dos agentes de campo, ignorando as orientações recebidas.

Mucelin et al. (2008) referem que o meio urbano é um espaço que, devido à elevada quantidade de resíduos sólidos gerados pela população com as atividades cotidianas, condiciona o morador a observar determinados fragmentos do ambiente sem perceber situações de graves impactos ambientais. Casos de agressões ambientais como poluição visual e disposição inadequada de resíduos em terrenos baldios refletem hábitos rotineiros em que o observador é compelido a conceber como normais.

Outro momento importante na pesquisa foi a entrevista realizada com a coordenação da VE. O foco da pesquisa foi baseado na coleta de dados no sistema de informação em saúde entre os anos 2014 e 2018 sobre o número de pessoas acometidas por doenças de notificação compulsória, relacionadas ao contato direto e indireto com resíduos sólidos e seu respectivo bairro e, assim, ter parâmetros e provas para associar a presença de resíduos em proximidades de domicílios e a evidência de doenças. Essas referências foram 
necessárias para facilitar a elaboração da pesquisa e o direcionar o percurso para a realização das fotografias.

Para a coordenação da VE, o principal problema ocasionado pelos terrenos baldios com resíduos tem sido o aumento do número de doenças notificadas como dengue, zika, leptospirose, hepatites e leishmaniose (Gráfico 1). A dengue apresentou maiores valores, cresceu 456,9\% em 2018 quando comparada a 2017.

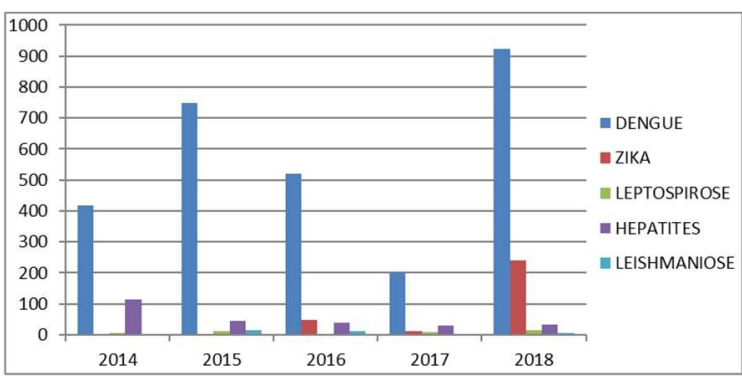

Gráfico 1: Doenças desencadeadas pelo contato com resíduos sólidos em Campina Grande/PB (20142018)

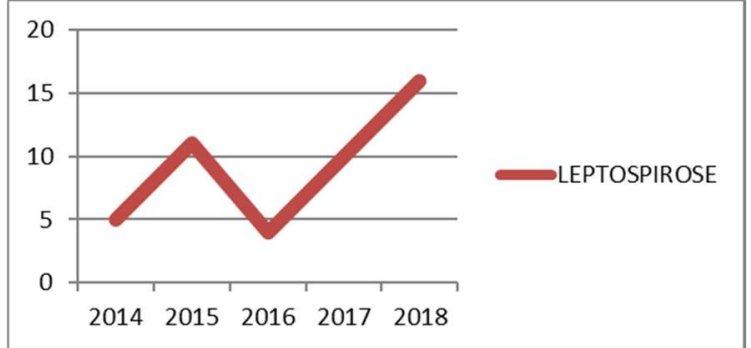

Gráfico 2: Notificação de casos de leptospirose em Campina Grande/PB (2014-2018).

A leptospirose também se apresentou elevada nos anos estudados, sobretudo entre 2016 a 2018 (Gráfico 2). Trata-se de uma zoonose generalizada e potencialmente fatal que é endêmica em muitas regiões tropicais e causa grandes epidemias após fortes chuvas e inundações (HAAKE et al., 2015).

As atribuições mencionadas pela VE para mitigar a deposição de resíduos em terrenos baldios e, consequentemente, atenuar as notificações de doenças correlacionadas foram: realizar capacitações junto aos profissionais da atenção básica, através da Estratégia Saúde da Família, apresentar números de registros de notificação de doenças e a situação epidemiológica como forma de reflexão para os profissionais de saúde, publicar o Boletim Epidemiológico, além de promover palestras à população, esta última, apenas quando solicitada.

A coordenação da VE fez referência ao fato de que, apesar de trabalhar em conjunto com os profissionais de saúde e com a VA, um dos principais obstáculos para a efetividade de suas ações é o precário saneamento básico em alguns locais; terrenos baldios sem os devidos cuidados de seus responsáveis e, ainda, a disseminação de doenças.

Muitas doenças consideradas epidemiológicas estão vinculadas à fragilidade da operacionalização dos serviços de saneamento básico nas cidades, dentre eles o gerenciamento dos resíduos sólidos urbanos. As doenças decorrentes do mau acondicionamento dos resíduos sólidos se dão pela disposição final ambientalmente inadequada dos mesmos, que se tornam locais favoráveis à proliferação de vetores, tais como insetos, moscas, baratas, roedores, os quais são responsáveis pela transmissão de diversas enfermidades ao ser humano (PEREIRA et al., 2018).

Ambiente sadio é fundamental para uma melhor qualidade de vida das pessoas no recinto das cidades. Para tanto, é necessário a realização do gerenciamento integrado dos resíduos sólidos urbanos, visto que o condicionamento inadequado dos resíduos implica em danos ambientais e sociais, sendo os mais graves relacionados à saúde. 


\section{Visitas in loco para registros fotográficos}

Para atestar as informações obtidas nas Vigilâncias Ambiental e Epidemiológica foram realizadas visitas nos oito DS de Campina Grande e bairros mais afetados com casos notificados de manifestação de doenças ocasionadas pelo convívio ou contato com resíduos sólidos.

A Figura 1 mostra um terreno baldio, a poucos metros de residências, com acúmulo de resíduos, atitude que parece ser uma prática comum por parte da população. Para a VE, a falta de limpeza nesses terrenos pode gerar problemas diversos em virtude desses acúmulos, como lugar de moradia e esconderijo de animais peçonhentos e de facilitar a proliferação de roedores e insetos, mau cheiro no ambiente e a presença de pessoas que fazem uso indevido do local. Outro problema ocasionado pela presença desses detritos nos terrenos abandonados ocorre em épocas de chuva, quando a enxurrada pode carregá-los, resultando em entupimento de bueiros e canais de escoamento de água (Figura 2), provocando alagamentos na região.

Segundo informações colhidas no momento dos registros fotográficos, vários moradores do entorno foram acometidos por doenças como dengue, zika, chikungunya, leptospirose e diarreias, trazendo repercussões sociais, pois além do adoecimento, ficaram impossibilitados em manter sua rotina diária, como frequentar escola e trabalho. Também foi informado que estes terrenos têm servido como cemitério para animais mortos, provocando sérios impactos ambientais.

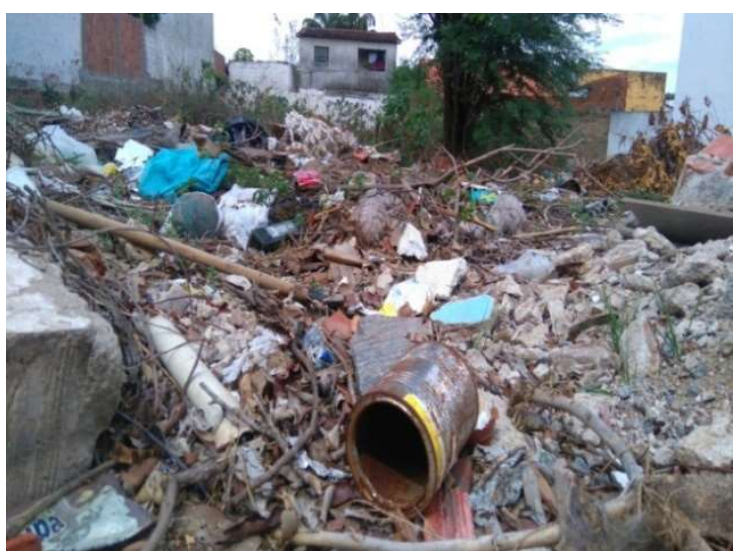

Figura 1: Bairro: Jardim Paulistano, Campina Grande/PB.

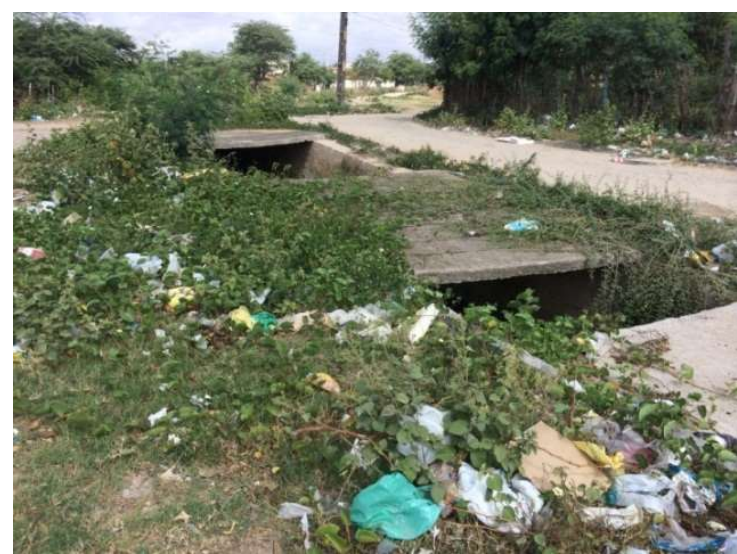

Figura 2: Bairro: Malvinas, Campina Grande/PB.

O Diagnóstico do Manejo de Resíduos Sólidos Urbanos (2016) do Sistema Nacional de Informações sobre a Gestão dos Resíduos Sólidos (SINIR), publicado em 2018, identifica os aspectos da gestão dos serviços de manejo dos resíduos sólidos nos municípios brasileiros. Em 2016, 65,9\% dos municípios brasileiros (3.670) participaram do Diagnóstico, representando 84\% da população urbana do país (146,3 milhões de pessoas). O documento revela que $98,6 \%$ dessa população urbana teve cobertura do serviço regular de coleta de resíduos domiciliares, enquanto aproximadamente 2,7 milhões de habitantes do país sofrem com o déficit da coleta desses resíduos, sendo $44,7 \%$ moradores da região Nordeste, $21,8 \%$ do Sudeste, $21,1 \%$ do Norte e 12\% dessa população dividida entre as regiões Sul e Centro-Oeste (BRASIL, 2018).

Aprovada em 2015, na Cúpula de Desenvolvimento Sustentável, em Nova lorque, a Agenda 2030 da 
ONU é "um plano de ação para as pessoas, o planeta e a prosperidade" que almeja "assegurar os direitos humanos de todos" (ONU, 2015). O documento intitulado de "Transformando Nosso Mundo: A Agenda 2030 para o Desenvolvimento Sustentável" apresenta 169 metas, distribuídas em 17 objetivos, os quais são normas pertencentes aos Regimes Internacionais do Meio Ambiente e do Desenvolvimento e busca "assegurar padrões de produção e de consumo sustentáveis" (ONU, 2015), que visam prevenir, reduzir, reciclar e reusar os resíduos de um modo geral.

Em vários bairros de Campina Grande pode-se perceber que os geradores de resíduos de construção civil não têm o devido cuidado com o armazenamento e destino adequado desses materiais. Formam entulhos a céu aberto nos terrenos baldios, causando uma impressão de desordem na obra (Figura 3) e desvalorização imobiliária para casas ou apartamentos que estejam à venda ou para alugar em locais próximos (Figura 4).

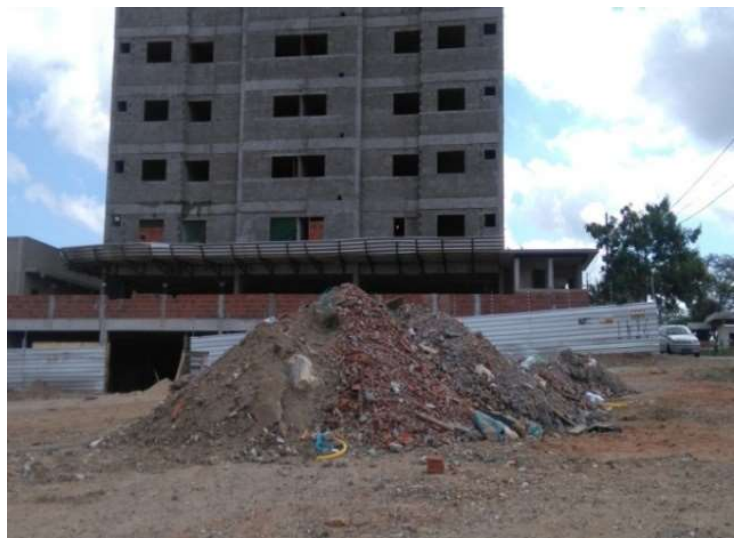

Figura 3: Bairro: Catolé, Campina Grande/PB.

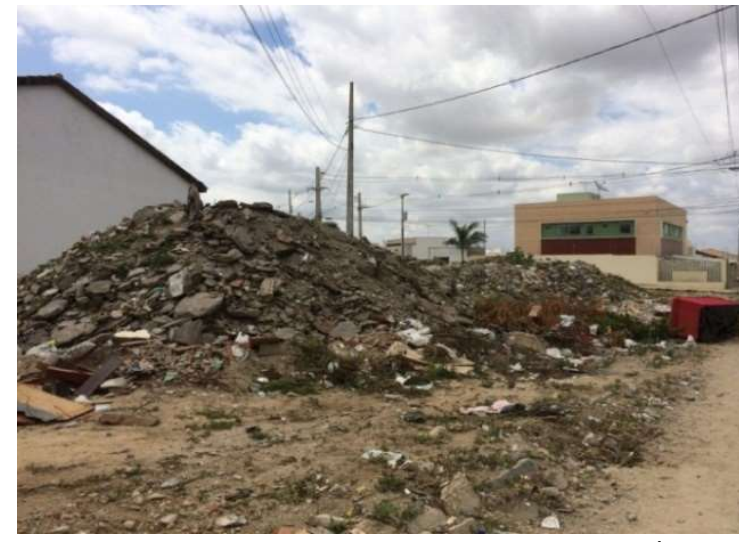

Figura 4: Bairro: Velame, Campina Grande/PB.

Conforme Mattos et al. (2013), a formação de pequenos lixões causa contaminação do solo e da água superficial e subterrânea, dispersão de plásticos e outros materiais, proliferação de insetos e vetores que afetam a saúde humana e também produz um impacto visual negativo com a consequente desvalorização de terras e propriedades vizinhas, conforme se verifica na figura 5. No percurso da pesquisa foi identificado que além dos terrenos baldios, as pessoas depositam resíduos em calçadas, impedido os pedestres caminharem de forma segura, podendo ocorrer, inclusive, acidentes automobilísticos quando transitam pelas ruas (Figura 6).

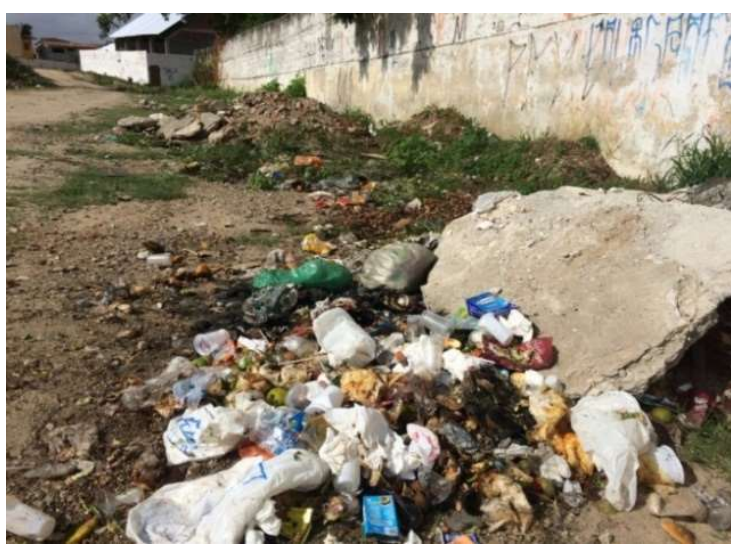

Figura 5: Bairro: Bela Vista, Campina Grande/PB.

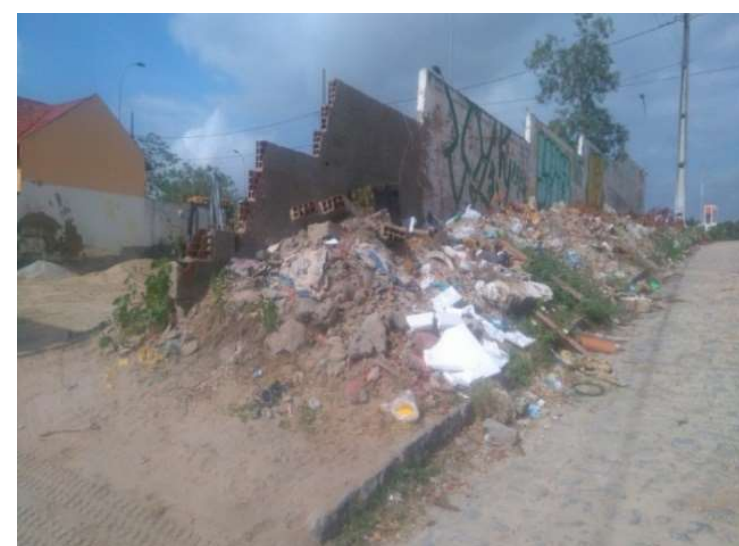

Figura 6: Bairro: Bodocongó, Campina Grande/PB. 
Para Pereira et al. (2018) existe um alto custo de uma má gestão de resíduos sólidos, assim como a economia feita com uma gestão eficaz. A integração do governo com a iniciativa privada e a sociedade civil, por meio da educação ambiental e das Tecnologias Sociais representa um importante passo para a superação dos desafios encontrados (ONU, 2015).

Moraes et al. (2017), defendem que o aumento da geração de resíduos sólidos é causado pela produção e pelo consumo de bens em larga escala, que é a base do modelo de crescimento econômico do sistema capitalista. Leff (2012) chama esse processo de crise ambiental que deu origem a um questionamento da racionalidade econômica dominante, assim como as ciências do conhecimento e saberes que serviram de suporte teórico e de meios instrumentais ao processo civilizatório, caracterizado pelo domínio do homem sobre a natureza. Durante a realização da pesquisa de campo, foram vistos vários resíduos volumosos em terrenos baldios e em calçadas como cadeira, vaso sanitário, colchão e sofá, conforme mostra a figura 7.

Mesmo tendo o conhecimento do importante trabalho dos coletores de resíduos secos, como papel, papelão, latas, garrafas pet, vidro, entre outros, muitas vezes sem equipamentos de proteção individual, nos impressiona vê-los dentro de lixões, em busca de algo. A cena da figura 8 foi uma das mais impactantes de todo o percurso da pesquisa. Decerto, realizam importante contribuição na preservação do meio ambiente, no entanto, põem suas vidas em riscos, não são reconhecidos pela sociedade, nem pelos poderes públicos.

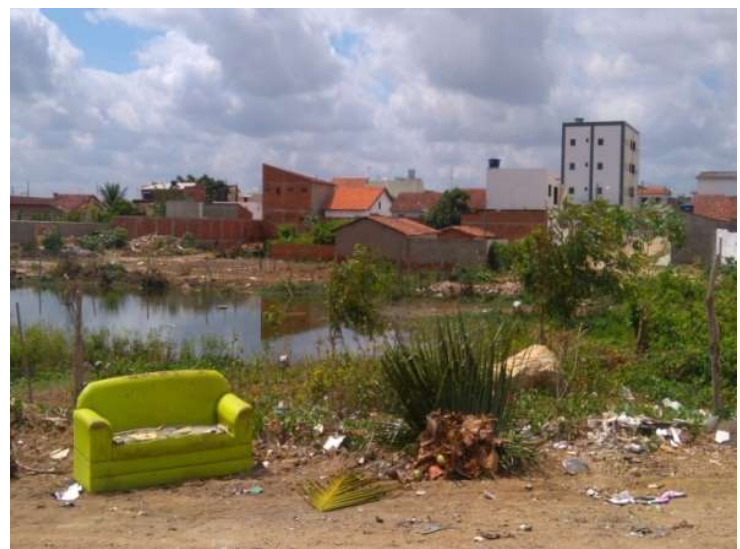

Figura 7: Bairro: Pedregal, Campina Grande/PB.

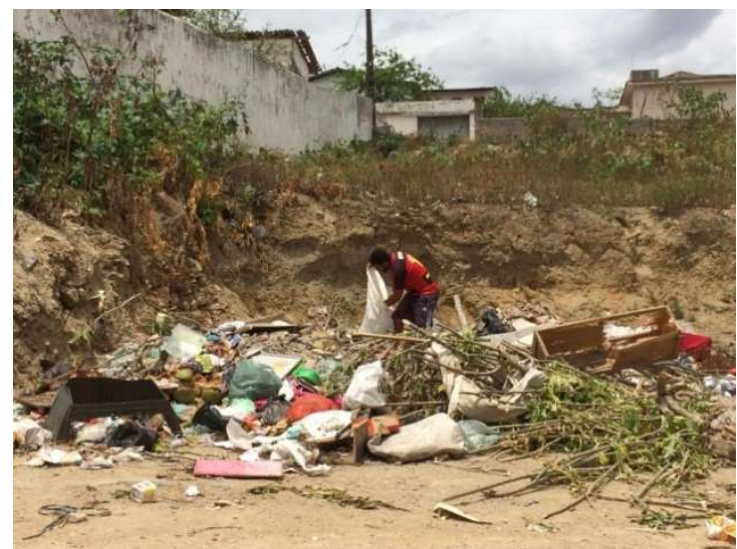

Figura 8: Bairro: Rosa Cruz, Campina Grande/PB.

Com base em um estudo investigativo sobre a sistematização das Estratégias de Ensino (EE) com foco na educação ambiental foi possível evidenciar, a partir dos resultados obtidos, certa carência quanto ao entendimento da educação ambiental no contexto educacional, ainda pouco explorada. A problematização para as práticas de educação ambiental decorre da necessidade de que estas sejam introduzidas no cotidiano escolar, na perspectiva da adoção de hábitos mais saudáveis. A sistematização das EE com foco na educação ambiental ainda é um desafio que precisa avançar (UHMANN et al., 2018).

A Declaração da Primeira Conferência Intergovernamental sobre Educação Ambiental, em Tbilisi, 1977, diz que:

A Educação Ambiental deve ser dirigida à comunidade, despertando o interesse do indivíduo em participar de um processo ativo no sentido de resolver problemas dentro de um contexto de realidades específicas, estimulando a iniciativa, o senso de 
responsabilidade e o esforço para construir um futuro melhor. (...) pode ainda contribuir satisfatoriamente para a renovação do processo educativo e que o objetivo da Educação Ambiental deva estar concentrado no desenvolvimento de uma compreensão integrada do meio ambiente em suas múltiplas e complexas relações.

Assim, a educação ambiental deve ser direcionada para a cidadania ativa considerando seu sentido de pertencimento e corresponsabilidade que, por meio da ação coletiva e organizada, busca a compreensão e a superação das causas estruturais e conjunturais dos problemas ambientais, pois o saber popular consegue proporcionar caminhos de participação para a sustentabilidade.

\section{Secretaria de Serviços Urbanos e Meio Ambiente (SESUMA)}

A Associação Brasileira de Empresas de Limpeza Pública e Resíduos Especiais - ABRELPE (2017) observa que a quantidade de resíduos disposta de maneira inadequada cresce a cada ano, trazendo impactos negativos ao meio ambiente e à saúde pública. Caso não sejam adotadas medidas urgentes para reverter esse quadro, é eminente o risco de atingir um problema de proporções irreversíveis, seja porque os custos de recuperação serão incalculáveis, seja devido às alternativas de recuperação que não surtirão mais efeito, tamanho o grau de degradação.

Diante da preocupante observação da ABRELPE (2017), foi substancial e oportuno contar com a participação da coordenação da SESUMA de Campina Grande, a fim de identificar junto a esta Secretaria quais as estratégias que o município tem praticado para mitigar a deposição de resíduos sólidos em terrenos baldios. Assim, a partir da entrevista semiestruturada, foi gerado três categorias para melhor descrever as informações: Resíduos sólidos em terrenos baldios; Educação ambiental e penalidades; Indicadores de sustentabilidade ambiental.

\section{Categoria 1 - resíduos sólidos em terrenos baldios}

A coordenadora da SESUMA tem várias atribuições e responsabilidades, tais como gerência de mobilização e educação ambiental; gerência de fiscalização e controle ambiental e gerência de coleta e tratamento de lixo. Sobre a frequência e assiduidade da coleta de resíduos em Campina Grande, afirma que:

O caminhão coletor de resíduos passa regularmente em todas as ruas da cidade. As pessoas depositam resíduos sólidos em terrenos baldios por questões culturais e não absorvem a ideia de que contribuir, também vai favorecer ela própria por estar preservando o meio ambiente, eliminando os vetores causadores de doenças, evitando a desvalorização de seu habitat, porque o resíduo também tem influências negativas na questão da estética e do visual. Penso que as pessoas têm essa prática provavelmente devido à ideia de que: o que não serve para mim pode 'jogar no mato', um termo antigo, porém ainda hoje se associa ao terreno baldio, como um lugar 'com mato e abandonado'.

Uma pesquisa de campo realizada em um bairro com alta incidência da febre chikungunya e dengue, $32 \%$ dos participantes afirmaram a existência de terrenos baldios próximos de suas residências, e $95 \%$ destes acham que esses terrenos contribuem para a disseminação de doenças, uma vez que estão sendo utilizados como depósito inadequado de resíduos sólidos domiciliares (SILVA et al., 2018).

\section{Categoria 2 - educação ambiental e penalidades}


Foi questionado se as pessoas, de forma geral, tinham acesso a informações sobre a educação ambiental e recebiam alguma orientação por parte da SESUMA, a resposta foi sim:

O nosso município tem várias iniciativas por meio das escolas municipais em que é trabalhado de forma mais intensa. A SESUMA atua não só com a informação, mas também com ação efetiva, contínua e prática por meio de panfletagem porta a porta, em eventos, através das mídias digitais, como Instagram (rede social), outdoor e totens.

Uma das finalidades da educação ambiental é despertar a preocupação individual e coletiva para a questão ecossistêmica por meio de uma linguagem de fácil entendimento que contribua para que a sociedade construa valores sociais, atitudes e competências voltadas à conservação do meio ambiente. Assim, torna-se necessário mudar o comportamento do homem em relação à natureza, com o objetivo de atender às necessidades ativas e futuras, no sentido de promover um modelo de desenvolvimento sustentável (SOARES et al., 2007).

A educação ambiental se constitui em um processo de contínua formação da população, com o intuito de desenvolver habilidades e modificar atitudes em relação ao meio, a partir da percepção ambiental, gerando uma comunidade consciente de seu papel e sua realidade global. Cada indivíduo percebe, reage e responde diferentemente às ações sobre o ambiente em que vive. As respostas ou manifestações daí decorrentes são resultado das percepções (individuais e coletivas), dos processos cognitivos, julgamentos e expectativas de cada pessoa (VILLAR et al., 2008).

A entrevistada também falou da importância de envolver a comunidade com essa problemática de terrenos sujos, sugeriu fazer um mutirão de limpeza, mostrando o antes e o depois, ou então, a própria comunidade fazer uma praça com plantio de mudas.

Foi investigado se havia conhecimento de situações em que algum morador tinha sido advertido por fiscais da prefeitura, porque estava depositando resíduos sólidos em terrenos baldios:

Sim, existem situações em que moradores pagaram uma tributação porque estava depositando resíduos em terrenos baldios no momento em que os fiscais da SESUMA passavam para realizar o trabalho de fiscalização diária. Caso a pessoa não pague a multa, vai para a dívida ativa e ela perde alguns direitos. Existem, inclusive, outras formas de a pessoa pagar sem ser necessariamente com dinheiro... ela faz alguma compensação ambiental, plantação de mudas... a proposta não é punir sempre através de multas, mas fazer primeiro um trabalho educativo e de orientação, até porque muitas dessas pessoas realmente não tinham o conhecimento dos prejuízos para o meio ambiente e, para elas, colocar resíduos em terrenos baldios era uma atitude normal.

Apesar de a proposta inicial da SESUMA não ser de punir com multas os crimes ambientais, se for necessário, executa sim as penas aos infratores, desde que haja a denúncia e/ou flagrante, até mesmo por uma fotografia. Dessa forma, fazendo-se cumprir o Princípio Poluidor Pagador (LIMA, 2014) cujo valor da multa depende da gravidade da infração e do potencial poluidor, em relação ao volume e tipo de resíduo e varia de 10 a 100 Unidades Fiscais de Campina Grande, sendo uma unidade equivalente a aproximadamente 50,00 reais.

Cotidianamente essas notificações são feitas, mas aí, depende do flagrante e da denúncia. Tem que ser uma denúncia efetiva com o endereço da pessoa, ou fotografia da placa de carro de alguém que parou em um terreno para colocar o resíduo, por exemplo..., e aí, não necessariamente é colocado resíduo domiciliar; tem gente que coloca resíduo de poda, 
embora a prefeitura ofereça esse serviço..., outros colocam pneu inservível, embora a prefeitura tenha um ponto de coleta para pneu inservível..., os resíduos volumosos, como colchão, sofá, a prefeitura também oferece um caminhão coletor de resíduos volumosos, é só a população solicitar, ligar e a prefeitura vai recolher.

Resíduo volumoso como sofá, colchão, vaso sanitário, pia e eletrodoméstico também é um incômodo para o ambiente. Segundo a Política Nacional de Resíduos Sólidos (PNRS), Lei 12.305/2010 (BRASIL, 2017), o Resíduo de Construção Civil e os Resíduos Volumosos são enquadrados na responsabilidade compartilhada, fazendo com que todo gerador tenha a incumbência no seu manejo e destinação adequada como o poder público local, grandes geradores, importadores, comerciantes, fabricantes, distribuidores e pequenos geradores.

O Plano de Gestão Integral de Resíduos Sólidos - PMGIRS (LIMA, 2014) de Campina Grande adota como diretriz principal a não geração, redução e máxima recuperação de resíduos e a minimização da quantidade de rejeitos levados à disposição final ambientalmente adequada, considerando a inserção socioeconômica dos catadores de materiais recicláveis e reutilizáveis, e as formas de responsabilidade dos setores públicos e privados, que são evidenciadas da diretriz principal do Plano Nacional de Resíduos Sólidos (BRASIL, 2011).

\section{Categoria 3 - indicadores de sustentabilidade ambiental}

No relato da entrevistada, os indicadores sociais, econômicos e ambientais que mais têm prejudicado a efetividade das ações e serviços da SESUMA são terrenos baldios sem os devidos cuidados de seus responsáveis e a falta de colaboração da população. Como forma estratégica para reduzir a prática da deposição de resíduos sólidos em terrenos baldios, a SESUMA sugere promover ações de integração junto à comunidade por meio de diferentes atores; utilizar a legislação e aplicar medidas punitivas para os infratores se for necessário; e que os donos de terrenos os mantenham cercados, limpos e urbanizados.

$\mathrm{Na}$ opinião da entrevistada, a educação ambiental e os indicadores de sustentabilidade podem contribuir diretamente com a sensibilização e também a redução de resíduos descartados de forma indevida. Gomes et al. (2012) afirmam que por meio da utilização de indicadores ambientais é possível analisar condições, mudanças da qualidade ambiental, além de favorecer o entendimento das interfaces da sustentabilidade e de tendências, como uma ferramenta de suporte no processo de tomada de decisão e formulação de políticas e práticas sustentáveis. Jorgensen (2005) ratifica: os indicadores têm como função diagnosticar a saúde do ecossistema e fornecer uma ferramenta para monitorar condições e mudanças ambientais ao longo do tempo.

O conceito de desenvolvimento sustentável vem de um processo longo, contínuo e complexo de reavaliação crítica da relação existente entre a sociedade civil com seu meio natural, assumindo diversas abordagens e concepções. Apresentar progresso em direção à sustentabilidade é uma escolha da sociedade, das organizações, das comunidades e dos indivíduos, devendo existir um grande envolvimento de todos os segmentos (VAN BELLEN, 2006).

Compete à Gerência de Mobilização e Educação Ambiental articular todos os órgãos da administração direta e indireta visando ações de mobilização e educação ambiental; elaborar e implementar um plano de 
educação ambiental no município; propiciar eventos e campanhas educativas atinentes a temas e datas ambientais; promover e realizar cursos e capacitações para potencializar a comunidade com intuito do desenvolvimento de ações ambientais; estimular ações objetivando o consumo consciente e atividades poupadoras de recursos naturais e, incentivar a participação popular nas ações e atividades planejando à defesa e preservação do meio ambiente (LEI COMPLEMENTAR 055/2011).

Em linhas gerais, a entrevista encerrou com a ideia de que o momento da pesquisa em si trouxe uma reflexão e a sensação da necessidade de criar um vínculo maior entre a SESUMA e as secretarias de educação e saúde e, assim, articularem meios mais efetivos no processo de educação ambiental. Ao término foi concordado que a população é a maior fiscalizadora de seu ambiente, todos são responsáveis pela preservação do meio ambiente e isto está instituído na PNRS (BRASIL, 2010), é a responsabilidade compartilhada.

\section{CONCLUSÕES}

É bastante relevante e indispensável a realização de coleta, tratamento e disposição final adequada dos resíduos sólidos, considerando-se essa prática como medida mitigadora dos impactos na saúde humana. Observa-se que a população em geral possui consciência dos prejuízos que os resíduos trazem a sua saúde, entretanto, pratica habitualmente a deposição inadequada. Talvez, isso seja decorrente do déficit de gerenciamento dos resíduos somado à fragilidade da educação ambiental das pessoas.

O panorama de gestão de resíduos sólidos no Brasil tem apresentado informações negativas em seus principais índices. As recomendações descritas na Política Nacional de Resíduos Sólidos ainda precisam de aplicações práticas e efetivas em todas as regiões do país.

A fim de mitigar a deposição inadequada de resíduos sólidos em terrenos baldios, a Vigilância Ambiental de Campina Grande sugere notificações e multas aos negligentes de cuidados ao ambiente, bem como fazer valer o Código de Postura do município. Com essa mesma perspectiva, a Vigilância Epidemiológica recomenda fazer campanhas mais impetuosas que estimulem práticas de educação ambiental, e para isso, precisa contar com o apoio de profissionais da educação e da saúde. A Secretaria de Serviços Urbanos e Meio Ambiente propõe-se a execução de ações que possam trazer benefícios à população, tais como maior incentivo à educação ambiental de forma que haja envolvimento dos diversos atores sociais: representantes do poder público, profissionais, lideranças comunitárias e moradores.

Amparado nessas proposituras, acredita-se que este estudo contribuiu para identificação de aspectos específicos de culturas e comportamentos ecológicos em um ambiente, servindo como ponto de partida para elaboração de instrumentos que permitam a compreensão desses constructos no âmbito populacional. Talvez, a utilização de metodologias ativas da aprendizagem auxilie novas práxis no processo de educação ambiental.

É importante acatar a ideia de que a educação ambiental desperta a preocupação individual e coletiva para a situação ecossistêmica. Para tanto, recomenda-se garantir o acesso à informação em linguagem adequada e compreensível, além de desenvolver uma consciência crítica, sensibilização e estímulo ao 
enfrentamento das questões ambientais e sociais. Provavelmente, para se alcançar este processo de desenvolvimento, deve-se procurar atentar não apenas à mudança cultural, mas também à transformação coletiva, entendendo que o comprometimento ambiental é uma questão ética, social, cultural e política.

Quanto maior o nível de educação ambiental de uma comunidade, mais eficazes serão as ações que visam à promoção da saúde, à prevenção de doenças e à conservação dos recursos naturais. É importante o incentivo a projetos de intervenção na realidade das escolas de todos os níveis educacionais para a consolidação de uma prática educativa que desenvolva valores diferentes em relação à forma como vemos, sentimos e vivemos.

\section{REFERÊNCIAS}

ABRELPE. Associação Brasileira de Empresas de Limpeza Pública e Resíduos Especiais. Panorama dos Resíduos Sólidos no Brasil. São Paulo: ABRELPE, 2017.

BARDIN, L.. Análise de Conteúdo. São Paulo: 70, 2015.

BRASIL. Ministério da Saúde. Cadastro Nacional de Estabelecimentos de Saúde (CNES). DATASUS, 2020.

BRASIL. Ministério das Cidades. Diagnóstico do Manejo de Resíduos Sólidos Urbanos, 2016. Brasília: MCIDADES, 2018.

BRASIL. Lei $\mathbf{n}$. 12.305, de $\mathbf{2}$ de agosto de 2010. Política Nacional de Resíduos Sólidos. 3 ed. Brasília: Câmara dos Deputados, 2017.

BRASIL. Ministério da Saúde. Resolução do Conselho Nacional de Saúde - N. 466, 12 de dezembro de 2012. Brasília: MS, 2012.

BRASIL. Ministério da Educação. Resolução n. 2, de 15 de junho de 2012. Diretrizes Curriculares Nacionais para a Educação Ambiental. Brasília: MEC, 2012.

BRASIL. Ministério do Meio Ambiente. Plano Nacional de Resíduos Sólidos. Brasília: MMA, 2011.

BRASIL. Ministério da Saúde. Secretaria de Vigilância em Saúde. Departamento de Vigilância Epidemiológica. Guia de Vigilância Epidemiológica. 7 ed. Brasília: Ministério da Saúde, 2009.

BRASIL. Ministério da Saúde. Conselho Nacional de Saúde. Subsídios para a construção da Política Nacional de Saúde Ambiental. Brasília: Ministério da Saúde, 2007.

BRASIL. Ministério do Meio Ambiente. Declaração da Primeira Conferência Intergovernamental sobre Educação Ambiental - Declaração de Tbilisi, 1977.

GASKELL, G.. Entrevistas individuais e grupais. In: BAUER, M. W.; GASKELL, G.. Pesquisa qualitativa com texto, imagem e som: um manual prático. 11 ed. Petrópolis: Vozes, 2013. p.64-89.

GIL, A. C.. Métodos e técnicas de pesquisa social. 6 ed. São Paulo: Atlas, 2008.

GOMES, P. R.; MALHEIROS, T. F.. Proposta de análise de indicadores ambientais para apoio na discussão da sustentabilidade. Revista Brasileira de Gestão e Desenvolvimento Regional, Taubaté, v.8, n.2, p.151-169, 2012.

GLASER, B.; STRAUSS, A.. The discovery of grounded theory: Strategies for qualitative research. New York: Aldine Publishing Company, 1967.

HAAKE, D. A.; LEVETT, P. N.. Leptospirosis in Humans. Current Topics in Microbiology and Immunology, v.387, p.65-97, 2015. DOI: http://doi.org/10.1007/978-3-662-45059-8 5

IBGE. Instituto Brasileiro de Geografia e Estatística. Portal do IBGE: Censo demográfico e cidades - anos pesquisados: 2010, 2017 e 2019. Rio de Janeiro: IBGE, 2019.

JORGENSEN, S. E.. Introduction. In: JORGENSEN, S. E.; COSTANZA, R.; XU, F. L.. Handbook of ecological indicators for assessment of ecosystem health. New York: CRC Press Taylor \& Francis Group, 2005.

LEFF, E.. Saber ambiental: sustentabilidade, racionalidade, complexidade e poder. 9 ed. Petrópolis: Vozes, 2012.

LIMA, J. D.. Plano Municipal de Gestão Integrada de Resíduos Sólidos de Campina Grande/PB (PMGIRS). João Pessoa: O Autor, 2014.

MALHOTRA, N.. Pesquisa de marketing: uma orientação aplicada. 4 ed. Porto Alegre: Bookman, 2006.

MATTOS, P. H.; ANELLO, L. F. S.; TAGLIANI, C. R. A.. Uma análise sistêmica do gerenciamento dos resíduos sólidos em nove municípios da zona sul do Rio Grande do Sul. Diálogos \& Ciência, v.33, p.45-49, 2013

MINAYO, M. C. S.. Amostragem e Saturação em Pesquisa Qualitativa: Consensos e Controvérsias. Revista Pesquisa Qualitativa, São Paulo, v.5, n.7, p.01-12, 2017.

MORAES, M. A.; THEIS, V.; VIER, M. B.; SCHREIBER, D.. Análise dos custos ambientais relacionados com a gestão de resíduos em indústrias químicas. RACE, Joaçaba, v.16, n.2, p.505-522, 2017.

MUCELIN, C. A.; BELLINI, M.. Lixo e impactos ambientais perceptíveis no ecossistema urbano. Sociedade $\&$ Natureza, 
v. 20, n. 1 , p. $111-124,2008$.

ONU. Organização das Nações Unidas. Transformando Nosso Mundo: a agenda 2030 para o desenvolvimento sustentável. Nova lorque: ONU, 2015.

PARAÍBA. Lei complementar n. 055, de 11 de março de 2011: Cria a Secretaria de Serviços Urbanos e Meio Ambiente no município de Campina Grande e dá outras providências. Campina Grande: DOE, 2011.

PARAÍBA. Lei complementar n. 003, de 09 de outubro de 2006: Promove a revisão do Plano Diretor do Município de Campina Grande. Campina Grande: DOE, 2006.

PEREIRA, U. A.; ALEIXO, N. C. R.. Os Resíduos Sólidos Urbanos como Condicionante de Doenças na Cidade de Manaus/AM. Revista Geonorte, v.9, n.31, p.32-53, 2018.

PHILIPPI JÚNIOR, A.; MALHEIROS, T. F.. Saneamento e Saúde Pública: integrando homem e ambiente. In: Saneamento, saúde e ambiente: fundamentos para um desenvolvimento sustentável. Barueri: Manole, 2005.

PHILIPPI JÚNIOR, A.; PELICIOLI, M. C. F.. Alguns pressupostos a educação ambiental. In: PHILIPPI JÚNIOR, A.; PELICIOLI, M. C. F.. Educação ambiental: desenvolvimento de cursos e projetos. 2 ed. São Paulo: Signus, 2002.

RODRIGUES, M. G. S.; COSTA, R. S. O.. A integração da educação formal e não-formal: participação e cidadania. Congresso Acadêmico Sobre Meio Ambiente e Desenvolvimento. Rio de Janeiro: FGV, 2004.

SILVA, C. O.; MIRANDA, M. A.; LESS, D. F. S.. Análise dos serviços de saneamento básico e a incidência de casos de Chikungunya no Bairro da Matinha em Santarém (PA). Revista Ibero Americana de Ciências Ambientais, v.9, n.6, p.133-146, 2018. DOI: http://doi.org/10.6008/CBPC2179$\underline{6858.2018 .006 .0015}$

SILVA, M. M. P.; SOUSA, J. T.; CEBALLOS, B. S. O.; FEITOSA, W. B. S.; LEITE, V. D.. Avaliação sanitária de resíduos sólidos orgânicos domiciliares em municípios do semiárido Paraibano. Revista Caatinga, Mossoró, v.23, n.2, p.87-92, 2010.

SINIR. Sistema Nacional de Informações Sobre a Gestão dos Resíduos Sólidos. Planos municipais de gestão integrada de resíduos sólidos, 2018.

SOARES, L. G. C.; SALGUEIRO, A. A.; GAZINEU, M. H. P.. Educação ambiental aplicada aos resíduos sólidos na cidade de Olinda, Pernambuco - um estudo de caso. Revista Ciências \& Tecnologia, v.1, n.1, p.1-9, 2007.

SOUZA, A. P. B.; SOUZA, P. M.. Resíduos sólidos urbanos dispostos em terrenos baldios: problemas ambientais e de saúde. In.: SOUZA, P. M.; SOUZA, A. P. B.; COSTA, L. L.. Saúde ambiental: um olhar reflexivo. Campina Grande: EPGRAF, 2013. p.204-224.

UHMANN, R. I. M.; VORPAGEL, F. S.. Educação ambiental em foco no ensino básico. Pesquisa em Educação Ambiental, v.13, n.2, p.53-68, 2018. DOI: http://dx.doi.org/10.18675/2177-580X.vol13.n2.p53-68

VAN BELLEN, H. M.. Indicadores de sustentabilidade: uma análise comparativa. 2 ed. Rio de Janeiro: FGV, 2006.

VILLAR, L. M.; ALMEIDA, A. J.; LIMA, M. C. A.; ALMEIDA, J. L. V.; SOUZA, L. F. B.; PAULA, V. S.. A percepção ambiental entre os habitantes da região noroeste do estado do Rio de Janeiro. Esc. Anna Nery, 2008, v.12, n.2, p.285-290. DOI: https://doi.org/10.1590/S1414-81452008000200013

A CBPC - Companhia Brasileira de Produção Científica (CNPJ: 11.221.422/0001-03) detém os direitos materiais desta publicação. Os direitos referem-se à publicação do trabalho em qualquer parte do mundo, incluindo os direitos às renovações, expansões e disseminações da contribuição, bem como outros direitos subsidiários. Todos os trabalhos publicados eletronicamente poderão posteriormente ser publicados em coletâneas impressas sob coordenação da Sustenere Publishing, da Companhia Brasileira de Produção Científica e seus parceiros autorizados. Os (as) autores (as) preservam os direitos autorais, mas não têm permissão para a publicação da contribuição em outro meio, impresso ou digital, em português ou em tradução. 